\title{
Morphofunctional Features of the Temporomandibular Joint
}

\author{
Aspectos Morfofuncionales de la Articulación Temporomandibular \\ "Paulo Sérgio Flores Campos; **Francisco Prado Reis \& *** José Aderval Aragão
}

\begin{abstract}
CAMPOS, P. S. F.; REIS, F. P. \& ARAGÃO, J. A. Morphofunctional features of the temporomandibular joint. Int. J. Morphol., 29(4):1394-1397, 2011.

SUMMARY: This article focuses on important morphofunctional features of the temporomandibular joint, particularly those related to the ultrastructure and anterosuperior attachment of the joint capsule and condylar position at the end of the mouth-opening movement.
\end{abstract}

KEY WORDS: Anatomy; Temporomandibular joint; Temporomandibular joint disc.

\section{INTRODUCTION}

The temporomandibular joint (TMJ) performs an essential role in the human body due to its participation in vital processes such as mastication/swallowing and speech.

Some features of the TMJ are not common in skeletal joints. The TMJ is a double bilateral synovial joint to a single bone, which is only observed in two other synovial articulations: the atlanto-occipital and the sacroiliac joints; the latter is considered by many authors as a synchondrosis. Besides, the bone surfaces of the TMJ are covered by fibrous, not cartilaginous tissue as is the case in the acromioclavicular and sternoclavicular joints (Ten Cate, 1998).

Despite the difficulty in classifying the TMJ from a morphofunctional point of view, it is best described as a synovial ginglymoid and sliding joint of complex biaxial movements, because it performs rotation, translation, right and left lateral excursion, protrusion and retrusion. This characterization is more directly related to the morphofunctionality of the TMJ, and it is worth stressing its capacity to perform one of the greatest sliding movements of synovial joints, which allows large mouth opening.

Mouth Opening. In the mouth-opening movement, there is first a mandibular condyle rotation inside the articular fossa, which allows partial opening of $2-2.5 \mathrm{~cm}$. Then, the condyle sliding movement on the articular eminence leads to a maximum mouth opening of $5 \mathrm{~cm}$ or more.

The condyle sliding movement is naturally limited by the anterior and superior insertion of the joint capsule at the anterior slope of the articular eminence (Figún \& Garino, 2003).

Johansson \& Isberg (1991), on the other hand, observed on arthrography that the anterior point of insertion of the capsule in relation to the vertex of the articular eminence may vary from 0 to $10 \mathrm{~mm}$ (mean value $=4 \mathrm{~mm}$ ).

Based on this finding, Isberg (2001) affirmed that during maximum mouth opening, the mandibular condyle moves to the vertex of the eminence, and hypermobility occurs when the vertex of the condyle extends further than the eminence vertex.

Heffez et al. (1995), however, called attention to the fact that less contrast could be injected in the superior joint space in cadavers (average of $1.2 \mathrm{ml}$ ) than in vivo (only 0.4 to $0.5 \mathrm{ml}$ ). This fact seems to create an observation bias in evaluation of the insertion of the TMJ capsule by means of intra-articular injection of contrast agent.

\footnotetext{
* Associate Professor, Department of Radiology, School of Dentistry, Federal University of Bahia, Brazil

** Chairman of Neuroanatomy, Tiradentes University, School of Medicine, Sergipe, Brazil

**** Adjunct Professor of Human Anatomy, Federal University of Sergipe (UFS) and Titular Professor, Medical School of Tiradentes University (UNIT), Aracaju, Sergipe, Brazil.
} 
Gerry (1954), Shore (1966), and Lovely \& Copeland (1981) considered that during the translation movement, the condyle is supposed to reach the articular eminence vertex and even extend a little beyond it.

More recently, Palacios et al. (1990) showed that during maximum mouth opening, the vertex of the condyle extends beyond the vertex of the articular eminence. Katzberg \& Westesson (1994) also affirmed that, at the end of the mouth-opening movement, the condyle is beyond the vertex of the articular eminence and opposes the anterior band and the thin intermediate zone of the articular disc.

In clinical and radiographic assessments, Muto et al. (1994) and Meti (2002), found that, for almost all their patients, the condyle extended beyond the vertex during maximum mouth opening. D'Ippolito et al. (2009), in turn, considered hypermobility in maximum mouth opening when the condyle, more precisely its vertex, extended beyond the vertex of the articular eminence.

Thus, one can see that the anterior superior insertion of the TMJ capsule and the amplitude of condyle translation remain controversial. There is no doubt, however, that capsule insertions determine the amplitude of the movements of the bone components in any joint.

Morphofunctional features of the TMJ. The insertion of the TMJ capsule in the temporal bone occurs posteriorly, along the anterior margin of the petrotympanic fissure; medially, at the base of the sphenoid spine; and laterally, at the articular tubercle and zygomatic process of the temporal bone. The inferior insertion of the capsule occurs at the condyle neck, posteriorly, laterally and medially, with the medial insertion higher than the lateral insertion; and on the outline of the articular surface, anteriorly.

Anatomic sections of the TMJ show that the anterior and superior insertion of the capsule occurs at a point closer to or further from the vertex of the articular eminence (Fig. $1)$.

Regarding the histologic features, the external layer of the articular capsule (fibrous stratum) is composed of connective tissue, and, thus, is resistant to stretching. In order to allow gliding of the condyle, the upper half of the capsule, above the articular disc (particularly the anterior and posterior aspects), is composed of collagen and elastic fibers, whereas the lower half of the capsule is composed only of collagen fibers (Ten Cate).

Thus, considering the anterior and superior insertion and the histologic characteristics of the articular capsule, it seems reasonable to suggest that at maximum mouth opening, the condyle extends, more or less, beyond the vertex of the articular eminence (Figure 2).

We believe that, in a vertex to vertex relationship, the condyle and the eminence have only a contact point, which does not seem to be a stable relationship to ensure maximum mouth opening. On the contrary, when the condyle extends beyond the eminence, the posterior aspect of the

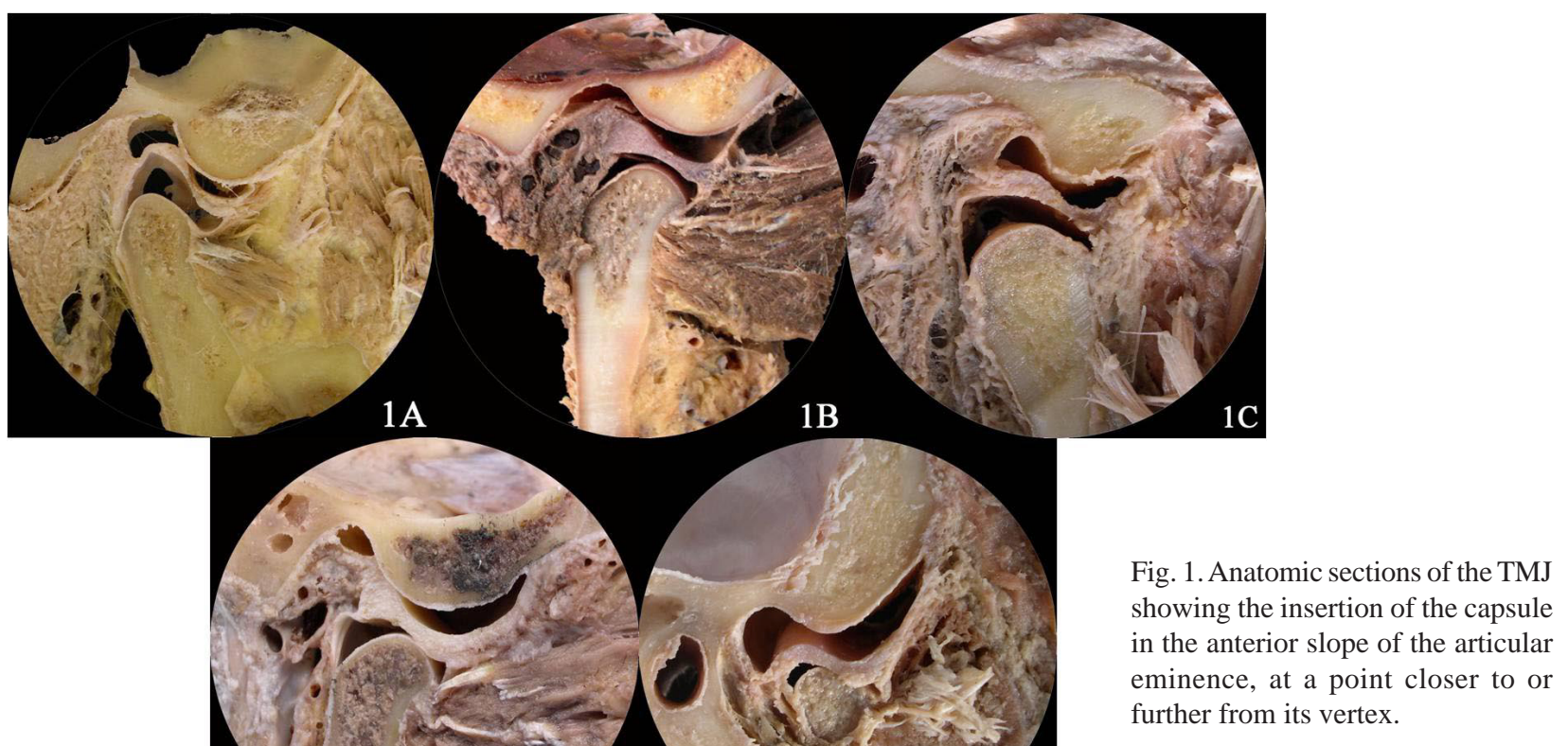




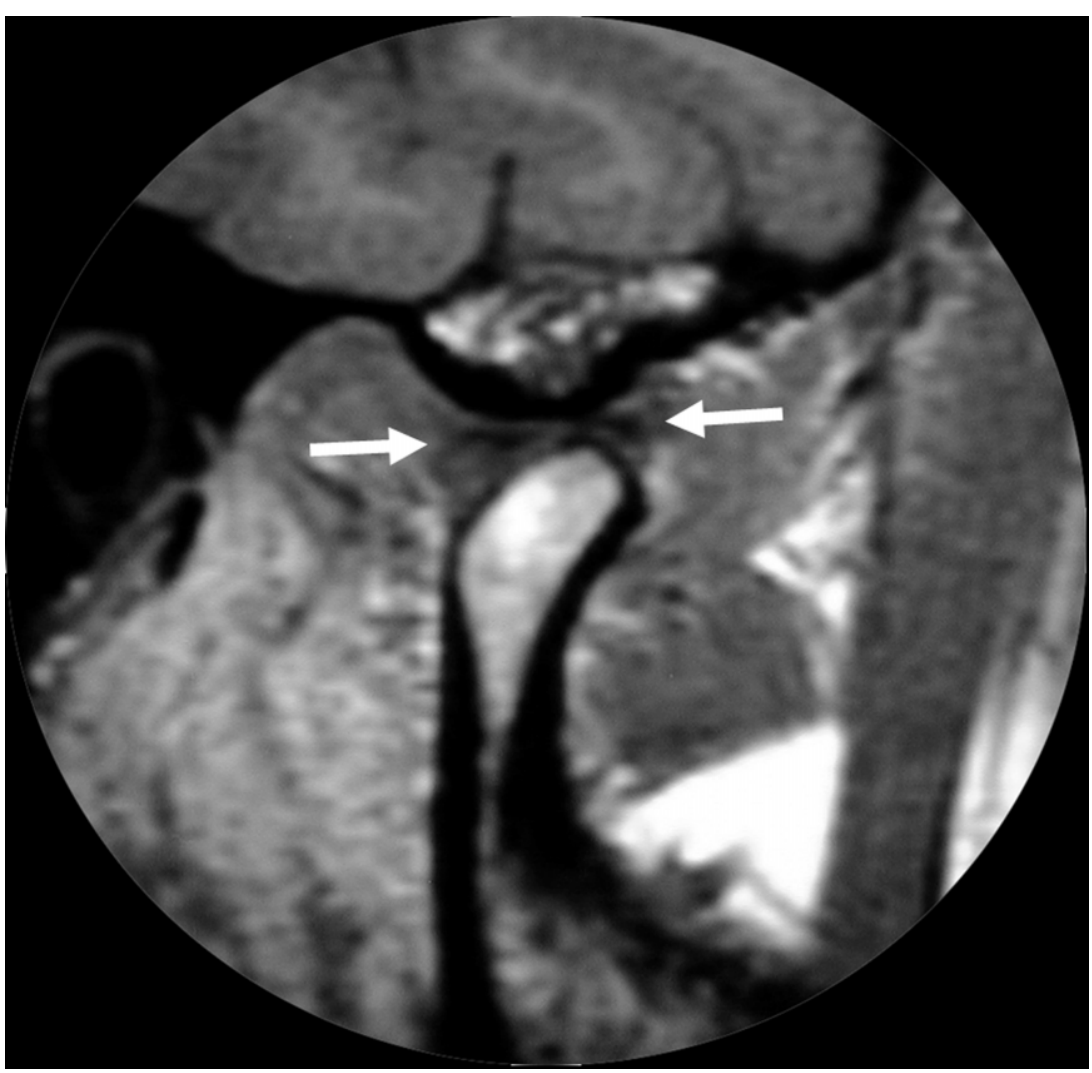

Fig. 2. Magnetic resonance image of the TMJ, right side, at maximum mouth opening, showing the posterior-superior aspect of the condyle/intermediate zone of the disc/anterior-inferior slope of the articular eminence, with the discal bands indicated (arrows).

condyle relates to the anterior slope of the eminence, establishing a contact surface between them, and, thus, generating a stable relationship for maintaining maximum mouth opening (Figure 3).
Moreover, in cases of TMJ dislocation (when the condyle glides abnormally along the anterior slope of the articular eminence, the muscles go into spasm and the individual is unable to close their mouth without professional intervention), there is no rupture of tissue, and, consequently, no edema, which demonstrates resistance to distension of the anterior aspect of the articular capsule.

In conclusion, we consider that when the condyle vertex extends to the articular eminence vertex, clinically there is no important limitation of mouth opening. On the other hand, we suggest that when the condyle vertex extends beyond the articular eminence vertex, at maximum mouth opening, there is no condyle hypermobility.

\section{ACKNOWLEDGMENT}

We thank CNPq (Conselho Nacional de Desenvolvimento Cientítico e Tecnológico - Brazilian Research and Technology Council) for support provided through the Scholarship for Research Productivity program.

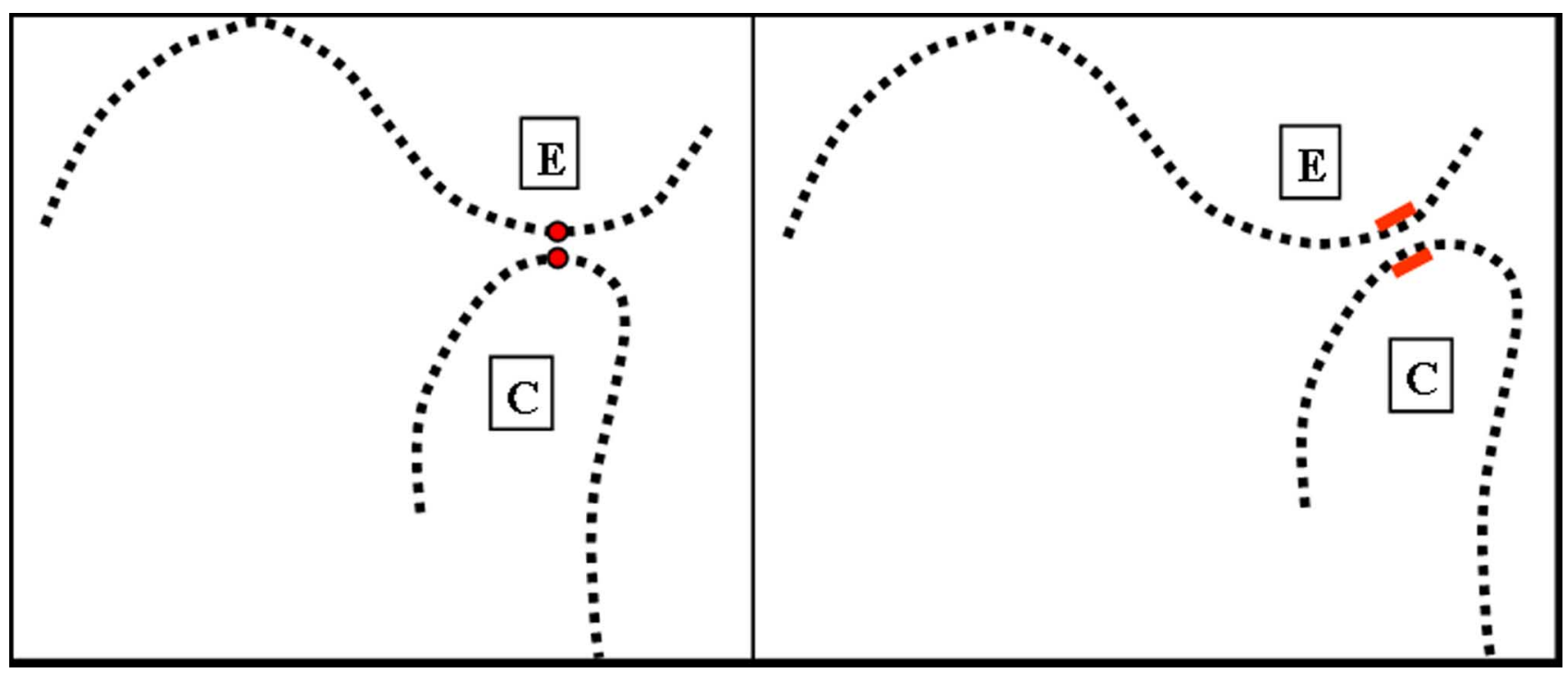

Fig. 3. Relationship between condyle/articular eminence: vertex to vertex (unstable) and surface to surface (stable). 
CAMPOS, P. S. F.; REIS, F. P. \& ARAGÃO, J. A. Aspectos morfofuncionales de la articulación temporomandibular. Int. J. Morphol., 29(4):1394-1397, 2011.

RESUMEN: Se focaliza importantes aspectos morfofuncionales de la articulación temporomandibular, especialmente aquellos relacionados a la ultraestructura e inserción antero-superior de su cápsula articular y la posición final del cóndilo, en el movimiento de apertura máxima bucal.

PALABRAS CLAVE: Anatomía; Articulación temporomandibular; Disco de la articulación temporomandibular.

\section{REFERENCES}

D’Ippolito, S. M.; Borri Wolosker, A. M.; D’Ippolito, G.; Herbert de Souza, B.; Fenyo-Pereira, M. Evaluation of the lateral pterygoid muscle using magnetic resonance imaging. Dentomaxillofac. Radiol., 39(8):494-500, 2009.

Figún, M. E. \& Garino, R. R. Anatomia odontológica funcional e aplicada. Porto Alegre, Artmed, 2003.

Gerry, R. G. Effects of trauma and hypermobility on the temporomandibular joint. Oral Surg. Oral Med. Oral Pathol., 7(8):87693, 1954.

Heffez, L. B.; Mafee, M. F. \& Rosenberg, H. Imaging atlas of the temporomandibular joint. Philadelphia, Williams \& Wilkins, 1995.

Isberg, A. Temporomandibular joint dysfunction: a practitioner's guide. Oxford, Isis Medical Media, 2001.

Johansson, A. S. \& Isberg, A. The anterosuperior insertion of the temporomandibular joint capsule and condylar mobility in joints with and without internal derangement. J. Oral Maxillofac. Surg., 49(11):1142-8, 1991.

Katzberg, R. W. \& Westesson P. L. Diagnosis of the temporomandibular joint. Philadelphia, Saunders, 1994.

Lovely, F. W. \& Copeland, R. A. Reduction eminoplasty for chronic recurrent luxation of the temporomandibular joint. J. Can. Dent. Assoc., 47(3):179-84, 1981.

Meti, M. Position of mandibular condyle at maximal mouth opening in symptom free subjects. Indian J. Dent. Res., 13(3-4):13541, 2002

Muto, T.; Kohara, M.; Kanazawa, M. \& Kawakami, J. The position of the mandibular condyle at maximal mouth opening in normal subjects. J. Oral Maxillofac. Surg., 52(12):1269-72, 1994.

Palacios, E.; Valvassori, G. E.; Shannon, M. \& Reed, C. F. Magnetic resonance of the temporomandibular joint: clinical considerations radiography, management. Stuttgart, Thieme, 1990.

Shore, N. A. Temporomandibular joint dysfunction: etiology, symptoms and management. Eye, Ear, Nose and Throat Monthly, 45:52-62, 1966.

Ten Cate, A. R. Oral histology: development, structure, and function. $5^{\text {th }}$ ed. St. Louis, Mosby, 1998.

Correspondence to:

Dr. Paulo Sérgio Flores Campos

Dpto. de Radiologia, Faculdade de Odontologia

Universidade Federal da Bahia

Av. Araújo Pinho, 62, Canela

CEP: $40.14-460$

Salvador - Bahia

BRASIL

Email: paulo@radiologia.odo.br

Received: 01-06-2011

Accepted: 05-09-2011 